\title{
Unexpected Diversity of Magnetococci in Intertidal Sediments of Xiaoshi Island in the North Yellow Sea
}

\author{
Haitao Chen, ${ }^{1,2}$ Jinhua Li, ${ }^{3}$ Xiang Xing, ${ }^{2}$ Zongjun Du, ${ }^{2}$ and Guanjun Chen ${ }^{2,4}$ \\ ${ }^{1}$ Deep-Sea Microbial Cell Biology, Department of Deep Sea Science, Sanya Institute of Deep-Sea Science and Engineering, \\ Chinese Academy of Sciences, 62 Fenghuang Road, Sanya 572000, China \\ ${ }^{2}$ College of Marine Science, Shandong University at Weihai, Weihai 264209, China \\ ${ }^{3}$ Key Laboratory of Earth and Planetary Physics, Institute of Geology and Geophysics, Chinese Academy of Sciences, \\ Beijing 100029, China \\ ${ }^{4}$ State Key Laboratory of Microbial Technology, Shandong University, Jinan 250100, China
}

Correspondence should be addressed to Guanjun Chen; guanjun@sdu.edu.cn

Received 24 July 2015; Revised 22 September 2015; Accepted 27 September 2015

Academic Editor: Masayuki Nogami

Copyright (C) 2015 Haitao Chen et al. This is an open access article distributed under the Creative Commons Attribution License, which permits unrestricted use, distribution, and reproduction in any medium, provided the original work is properly cited.

Magnetotactic bacteria (MTB) are a group of prokaryotes that, despite their high morphological, phylogenetic, and ecological diversity, share a common capability of forming intracellular nanocrystals of magnetite $\left(\mathrm{Fe}_{3} \mathrm{O}_{4}\right)$ or greigite $\left(\mathrm{Fe}_{3} \mathrm{~S}_{4}\right)$, called magnetosomes, and swimming along geomagnetic field lines in a process called magnetotaxis. In this study, we investigated the MTB diversity within the intertidal sediments near Xiaoshi Island (Weihai) in the North Yellow Sea using a combination of molecular ecology techniques and transmission electron microscopy (TEM). The combination of restriction fragment length polymorphism (RFLP) analysis and 16S rRNA gene sequencing revealed seven new MTB genera affiliated with the Alphaproteobacteria class. Fluorescence in situ hybridization (FISH) analyses suggested that one magnetotactic coccus (designated as WHI-2) is the dominant species. TEM observations and energy dispersive X-ray analyses revealed that MTB cells mainly form magnetite magnetosomes that are organized into two chains of magnetosomes composed of e-prismatic magnetite crystals. This finding suggests the adaptation of a magnetotactic bacterial population to the marine tide. This is the first report of magnetotactic bacteria near Xiaoshi Island, which should be useful for studies of biogeochemical cycling and the geohistory of this area.

\section{Introduction}

Magnetotactic bacteria (MTB) are a group of prokaryotes that, despite their high morphological, phylogenetic, physiological, and ecological diversity, share one common capability of swimming along geomagnetic field lines, a process called magnetotaxis $[1,2]$. This behavior is based on the dedicated intracellular organelle, the magnetosome, which consists of chain-structured nanocrystals of magnetite $\left(\mathrm{Fe}_{3} \mathrm{O}_{4}\right)$ or greigite $\left(\mathrm{Fe}_{3} \mathrm{~S}_{4}\right)$ [3]. The chain structure of magnetosomes maximizes the total magnetic moment of the MTB cells, thus allowing MTB to sensitively follow geomagnetic field lines and to efficiently search for their favorite habitats within aquatic environments $[4,5]$. Due to the unique biological and magnetic features of magnetosomes, MTB have long been of interest not only in biosciences and geosciences but also in nanomaterial science [6-8].
MTB are globally distributed and have been detected in various aquatic environments including lakes, rivers, ponds, estuary, lagoons, and marine sediments [9-17]. Petermann and Bleil discovered MTB in pelagic and hemipelagic sediments of the eastern South Atlantic Ocean, extending known MTB habitats to the deep sea [18]. Recently, MTB have also been found in various extreme environments $[19,20]$. Morphologically, the MTB discovered so far include cocci, ovoid, bean-shaped, rod-shaped, spirilla, and multicellular bacteria [11-14]. Phylogenetically, most known MTB belong to the Proteobacteria phylum, including the Alpha-, Gamma-, and Deltaproteobacteriaclasses [21, 22]. Several uncultured MTB communities are affiliated with the Nitrospirae phylum, and one magnetotactic bacterium, strain SKK-01, is within Omnitrophica phylum [16]. Considering their worldwide distribution and highly phylogenetic diversity, MTB may 
have played an important role in the past geochemical cycling of iron and may continue to do so [23], and their magnetic remains (i.e., magnetofossils) may have contributed significantly to the natural remnant magnetization of some marine and lake sediments $[9,10]$.

Despite their worldwide distribution and highly phylogenetic diversity, MTB are extremely fastidious and, therefore, difficult to isolate and grow. In the past 40 years, only a few strains have been isolated and purely cultured in the lab, and two Magnetospirillum strains (i.e., Magnetospirillum magneticum AMB-1 and Magnetospirillum gryphiswaldense MSR1) have been extensively and deeply studied to understand the molecular mechanisms of magnetosome formation [24, 25]. Culture-independent studies on uncultured MTB within natural environments are still essential for better understanding the diversity and geological contribution of such intriguing microorganisms. In this study, we investigated the phylogenetic diversity and morphological features of MTB within the intertidal sediments near Xiaoshi Island (Weihai) using a combination of molecular ecology techniques and transmission electron microscopy (TEM). Seven new MTB genera affiliated with the Alphaproteobacteria class were detected by $16 \mathrm{~S}$ rRNA gene sequencing, and one dominant magnetotactic coccus was characterized in detail using TEM.

\section{Materials and Methods}

2.1. Field Sampling and Set-Up of Microcosms. Marine sediments were collected from the surface layer $(\sim 3$ to $5 \mathrm{~cm})$ of the intertidalite near Xiaoshi Island (Weihai, north latitude $37^{\circ} 31^{\prime} 14.18^{\prime \prime}$ and east longitude $122^{\circ} 01^{\prime} 05.11^{\prime \prime}$ ) in the North Yellow Sea. The $\mathrm{pH}$, temperature, and salinity of sediments measured at the moment of sampling were $8.1,18.5^{\circ} \mathrm{C}$, and $28.9 \%$, respectively. To set up microcosms, approximately $400 \mathrm{~mL}$ of sediments was transferred to 1-liter plastic bottles covered with $\sim 100 \mathrm{~mL}$ of sea water from the sampling sites, covered loosely, and stored at room temperature in dim light. The quantity and community of MTB in the microcosms were periodically checked with the hanging drop method using an optical microscope (Olympus BX41) [26-28].

2.2. Magnetic Collection and Sample Preparation. Collection of MTB was performed by a two-step magnetic collection strategy as described previously [29]. Briefly, MTB cells were first collected from sediments in microcosms by attaching small magnets to bottles above the sediment surface with the magnetic S-pole toward the bottles. Collected MTB were then purified from nonmagnetic contaminations by a homemade "MTB trap" [30] or glass capillary [31]. The purified MTB cells were then washed with sterile distilled water twice and resuspended in $100 \mu \mathrm{L}$ of sterile distilled water for TEM and PCR amplification.

2.3. Transmission Electron Microscopy (TEM). For TEM observations, approximately $10 \mu \mathrm{L}$ of MTB cells was deposited onto a Formvar-supported, carbon-coated copper grid. After drying for $4-6 \mathrm{~h}$ at room temperature, the copper grids were cleaned with sterile distilled water approximately 5 times and dried in air. TEM experiments were performed on a JEM-2100 TEM with an accelerating voltage of $200 \mathrm{kV}$, equipped with an Oxford SDD detector $\left(\mathrm{X}-\mathrm{Max}^{\mathrm{N}} 80 \mathrm{~T}\right)$. In that condition, the chemical composition and crystal structure of magnetosomes were also determined by energy dispersive X-ray spectroscopy (EDXS) and selected area electron diffraction (SAED), respectively [32].

2.4. PCR Amplification and RFLP Analysis. 16S rRNA gene sequences of magnetotactic bacteria were amplified as described previously by Lin et al. [13]. Polymerase chain reactions (PCR) were then carried out with the following cycle: a $6 \mathrm{~min}$ initial denaturing step at $94^{\circ} \mathrm{C}$, followed by 30 cycles of $45 \mathrm{~s}$ at $94^{\circ} \mathrm{C}, 45 \mathrm{~s}$ at $53^{\circ} \mathrm{C}$, and $1.5 \mathrm{~min}$ at $72^{\circ} \mathrm{C}$, and a final extension step of $10 \mathrm{~min}$ at $72^{\circ} \mathrm{C}$. PCR products were checked by electrophoresis in $1 \%$ agarose gels and by ethidium bromide staining. PCR products were ligated into the pMD18-T cloning vector (Takara, Japan) and transformed into Escherichia coli $\mathrm{DH} 5 \alpha$ to construct a $16 \mathrm{~S}$ rRNA gene clone library. Positive clones were selected by blue-white screening and confirmed by PCR. PCR products containing the $16 \mathrm{~S}$ rRNA gene sequences from positive clones were digested at $37^{\circ} \mathrm{C}$ with $M s p I$ and RsaI (Takara, Japan) for $3 \mathrm{~h}$ prior to RFLP analysis and were separated in $4 \%$ agarose gels. Clones with different band patterns were sequenced by Shanghai Sunny Biotechnology Co., Ltd.

2.5. Phylogenetic Analysis. The partial and full-length $16 \mathrm{~S}$ rRNA gene sequences retrieved in this study were first analyzed using the BLAST search program on the NCBI website (http://blast.ncbi.nlm.nih.gov/Blast.cgi). The related sequences were preliminarily aligned with the default setting of CLUSTALW [33]. Phylogenetic tree analysis was performed with the software of MEGA 6.0 using the neighborjoining method. To validate the reproducibility of the branching pattern of the tree, a bootstrap analysis of 1000 replicates was performed. The sequences retrieved in this study were submitted in GenBank database with accession numbers KT327168-KT327175.

2.6. Fluorescence In Situ Hybridization. In this study, we designed a specific oligonucleotide probe: $5^{\prime}$-CTTTCCCTCTTGAGGCTTATGC-3' (positions 166 to 187), designated WHI-166. The bacterial universal probe EUB338 $\left(5^{\prime}-\right.$ GCTGCCTCCCGTAGGAGT-3', positions 338 to 355, E. coli numbering) was used as a control [34]. The specificity of the probe was evaluated through the Ribosomal Database Project II (RDP-II) in the PROBE_MATCH program and through the NCBI website $[34,35]$. The specific oligonucleotide DNA probe was labeled at the $5^{\prime}$ end with hydrophilic sulfoindocyanine Cy3, and the general probe was labeled at the $5^{\prime}$ end with phosphoramidite FAM. Both probes were synthesized and fluorescently labeled by Invitrogen Co., Ltd.

Magnetically enriched MTB cells were fixed with $4 \%$ paraformaldehyde as described by Pernthaler et al. Then, the cells were washed in $1 \times \mathrm{PBS}$ and stored in ethanolPBS $(1: 1)$ at $-20^{\circ} \mathrm{C}$. Approximately $20 \mu \mathrm{L}$ of fixed cells was dropped onto a glass slide prepared by coating with gelatin. A second fixation (dehydration) was performed by applying increasing concentrations of ethanol at 50, 80, and $100 \%$, 
TABLE 1: Magnetotactic cocci morphotypes present in the sampled sediments, based on TEM.

\begin{tabular}{|c|c|c|c|c|c|c|}
\hline \multirow{2}{*}{\multicolumn{2}{|c|}{ Size diameter $(\mu \mathrm{m})$}} & \multirow{2}{*}{ Number of magnetite chains } & \multirow{2}{*}{ Number of crystals per cell } & \multicolumn{2}{|c|}{ Crystals mean sizes (nm) } & \multirow{2}{*}{ Number of magnetosomes } \\
\hline & & & & Length $(\sigma)$ & Width $(\sigma)$ & \\
\hline $\mathrm{MC} \mathrm{a}$ & $\sim 2$ to 3 & 2 & $\sim 19$ & $140(46)$ & $111(38)$ & 57 \\
\hline $\mathrm{MC} \mathrm{b}$ & $\sim 1.5$ to 3 & 2 & $\sim 21$ & $128(35)$ & $107(32)$ & 165 \\
\hline $\mathrm{MC} \mathrm{c}$ & $\sim 2$ to 2.5 & 2 & $\sim 23$ & $115(37)$ & $96(34)$ & 91 \\
\hline $\mathrm{MC} \mathrm{d}$ & $\sim 1$ to 2 & 2 & $\sim 24$ & $122(28)$ & $107(23)$ & 195 \\
\hline $\mathrm{MC} \mathrm{e}$ & $\sim 1$ to 2 & 2 & $\sim 22$ & $112(31)$ & $96(26)$ & 169 \\
\hline $\mathrm{MC} \mathrm{f}$ & $\sim 1$ & 2 & 15 & $118(30)$ & $106(24)$ & 15 \\
\hline MC g & $\sim 2$ & 1 & 9 & $130(37)$ & $122(33)$ & 9 \\
\hline $\mathrm{MCh}$ & $\sim 1.5$ to 2 & Irregular & $\sim 22$ & $82(18)$ & $58(12)$ & 136 \\
\hline MC i & $\sim 1.5$ & Irregular & 19 & $68(13)$ & $51(11)$ & 19 \\
\hline
\end{tabular}

Note: $\sigma$ : standard deviation.
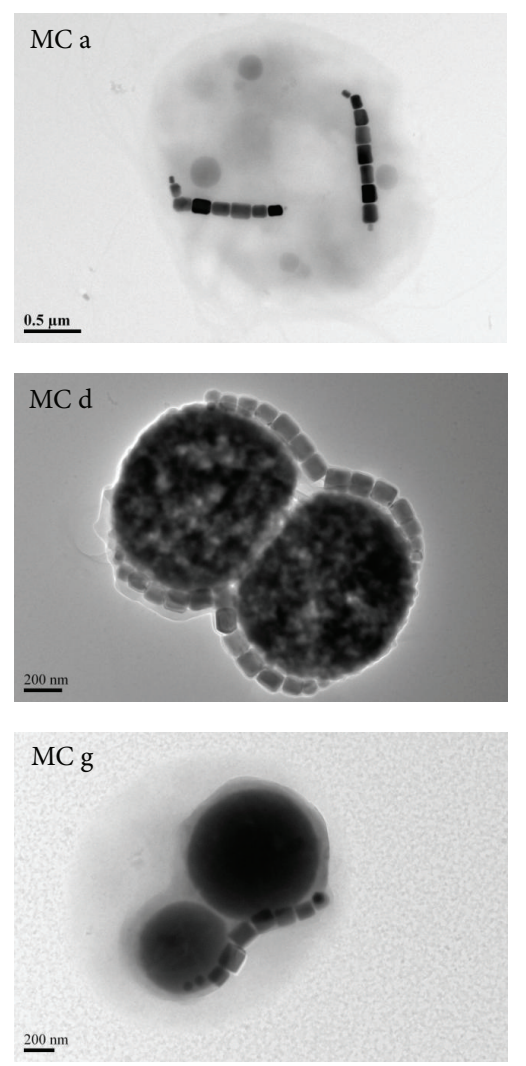
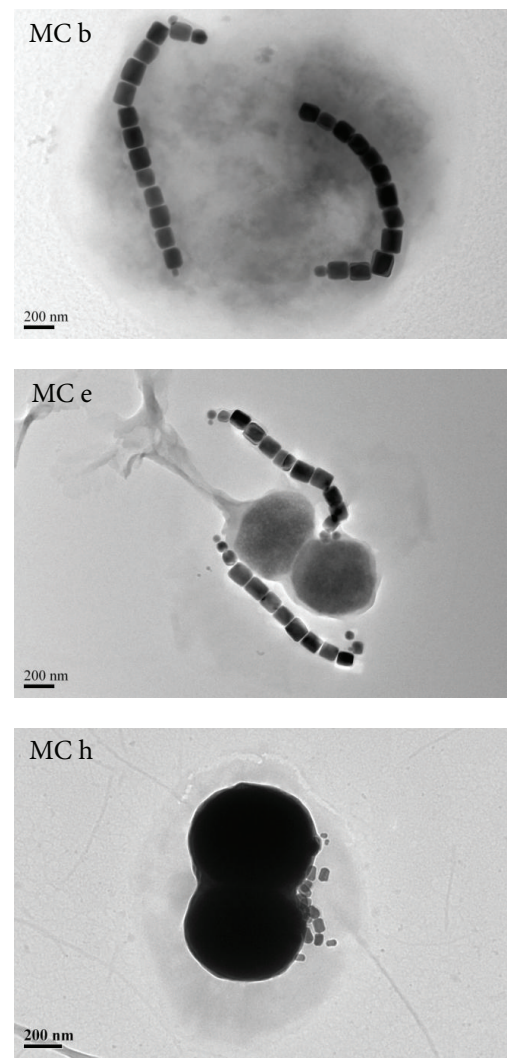
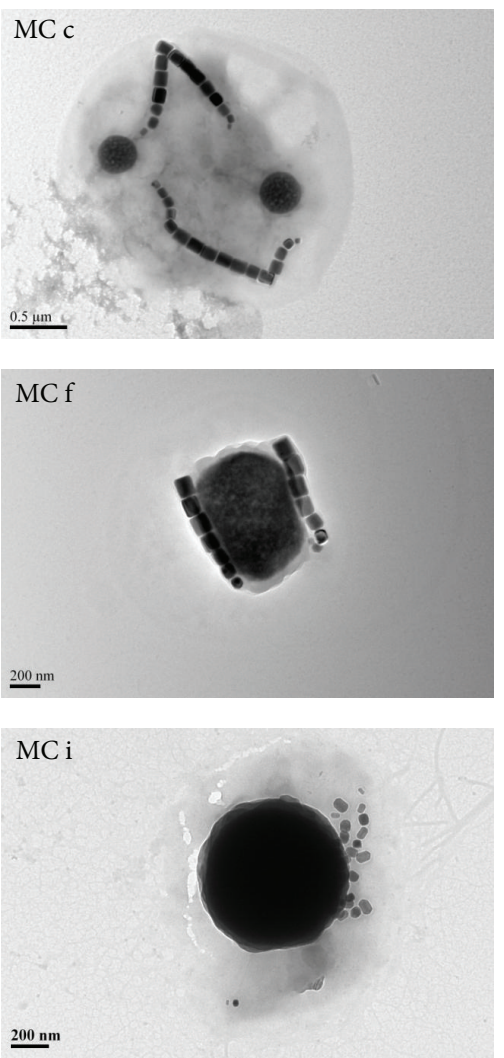

FIGURE 1: Morphologies of the enriched MTB cells. These MTB include nine morphotypes of magnetococci with elongated prismatic magnetosomes (designated MC a to MC i).

respectively. Then, $1 \mu \mathrm{L}$ of probe $(50 \mathrm{ng} / \mu \mathrm{L})$ was mixed with $9 \mu \mathrm{L}$ of hybridization buffer and used for fluorescence in situ hybridization, at $46^{\circ} \mathrm{C}$ for $3 \mathrm{~h}$ in hybridization buffer with $35 \%$ deionized formamide. The samples were washed with elution buffer for $25 \mathrm{~min}$ at $48^{\circ} \mathrm{C}$, rinsed with water, and stained with $4^{\prime}, 6^{\prime}$-diamidino-2-phenylindole (Sigma), and the samples were washed and dried again. The results were recorded using a fluorescence microscope (Olympus BX51) [36-38].

\section{Results and Discussion}

3.1. Morphological and Chemical Features of MTB. As MTB are adapted to complex chemical gradients, it is very difficult to isolate and cultivate these cells in the laboratory. However, they were found to be of high abundance and ubiquitous in both marine and freshwater habitats. Using the hanging drop method, the MTB of sediment samples were detected and observed. The density of cells is up to $10^{4}-10^{5}$ cells $/ \mathrm{cm}^{3}$. The dominant morph type of the enriched MTB from 

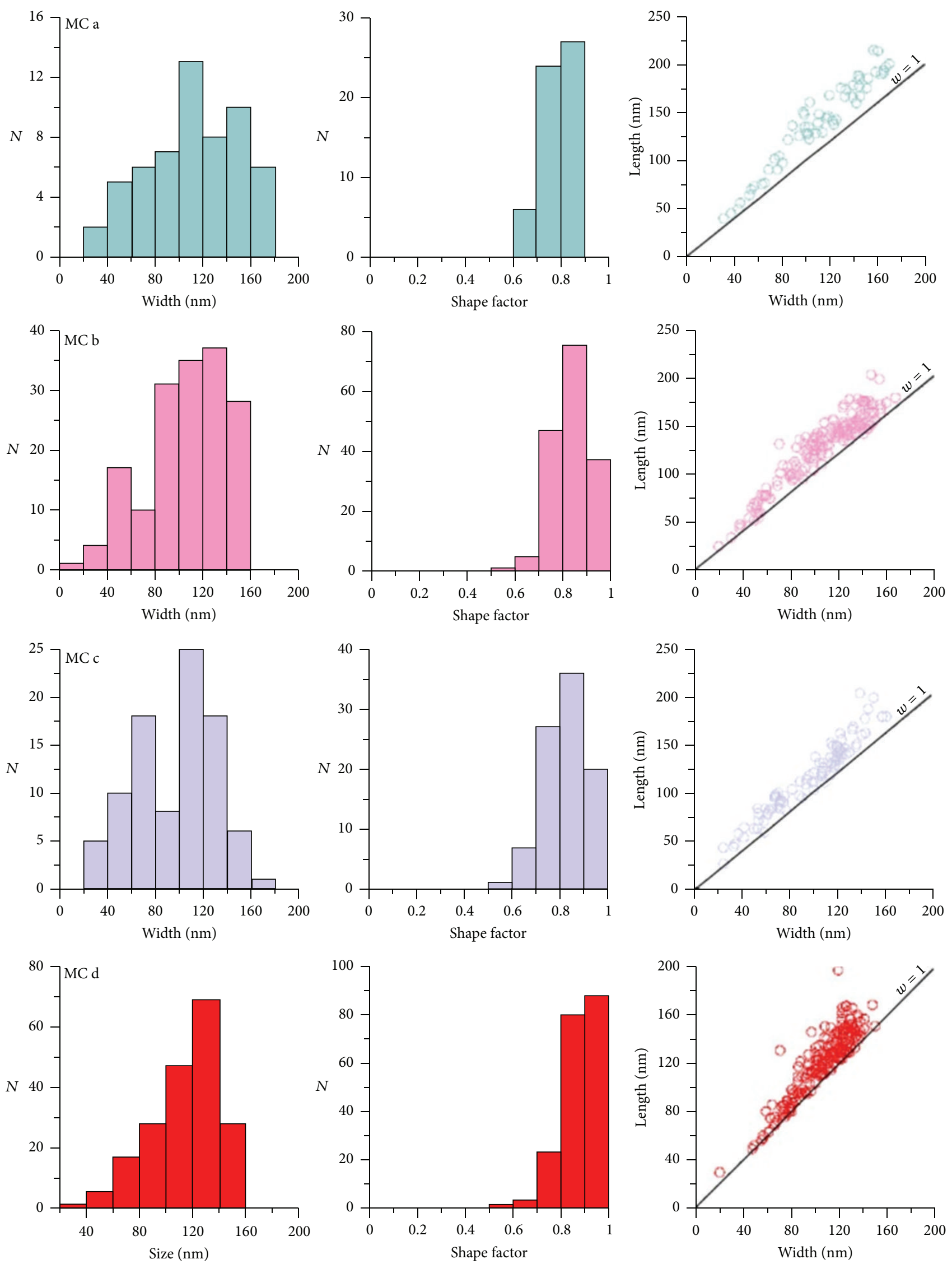

Figure 2: Continued. 

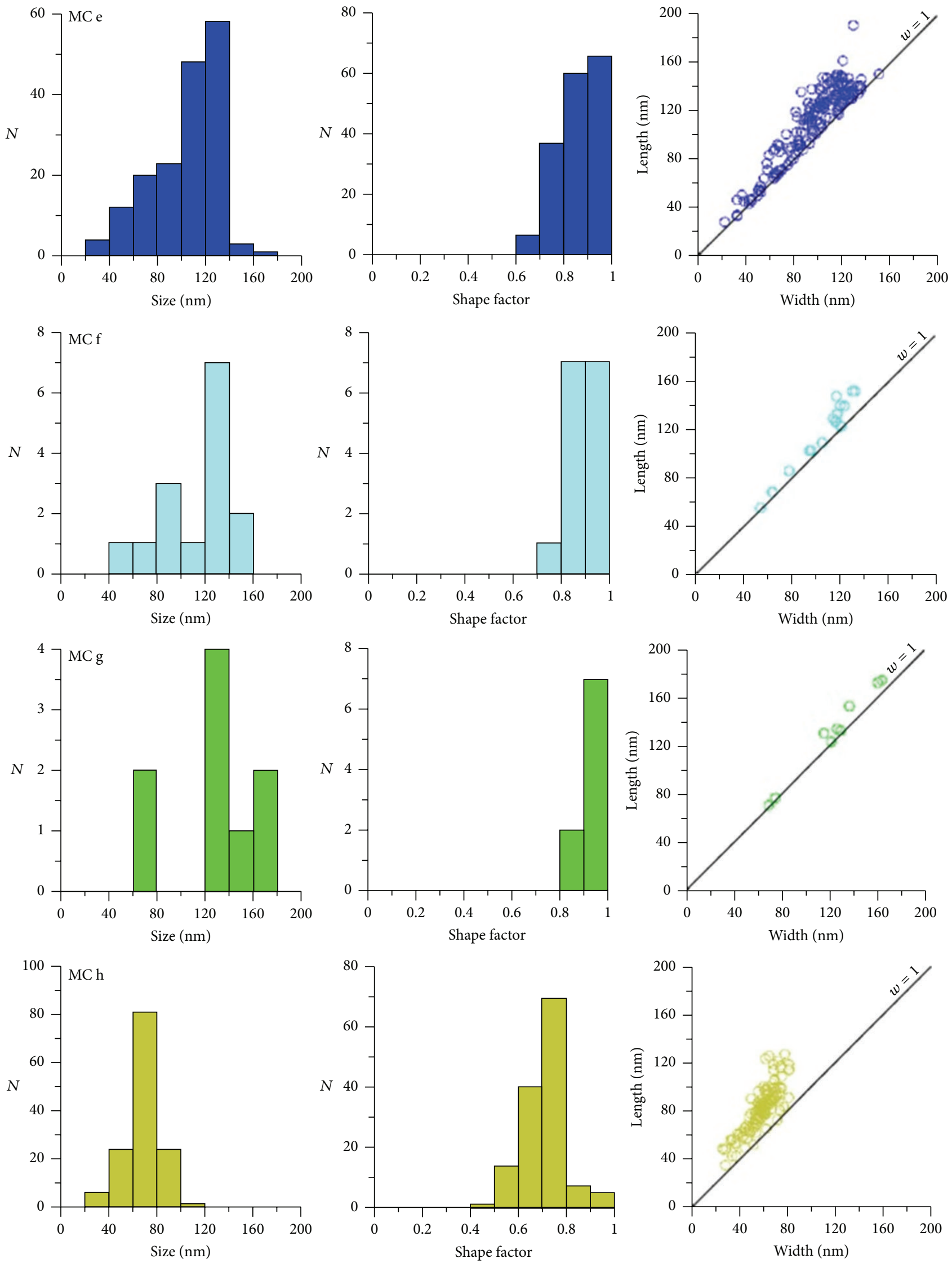

FIgURE 2: Continued. 

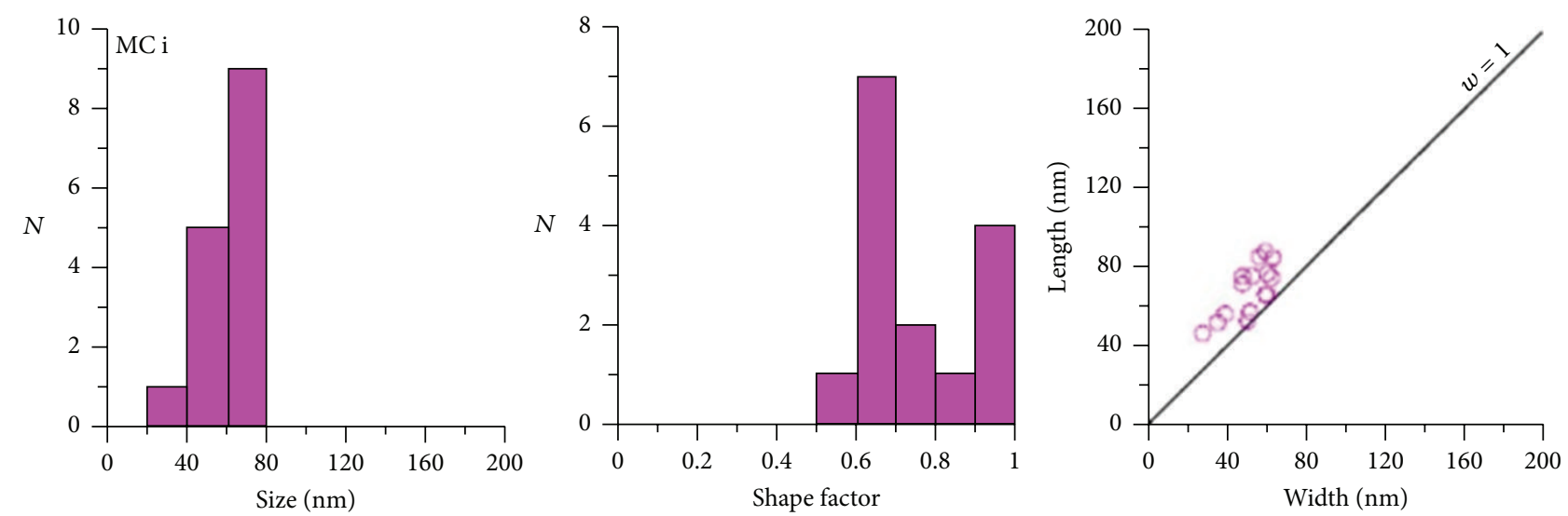

FIGURE 2: Size and shape distributions of magnetite crystals observed in the cumulated magnetococci. Size distribution, shape factor distribution, and scatter plot of length and width of magnetosomes in MC a to MC i. Each color corresponds to a single strain.

Xiaoshi Island was a coccid-to-ovoid cell shape of various dimensions. The morphotypes are defined principally on the basis of morphology, including cell size, magnetosome chains, magnetite crystals, and inclusion particles in cells. Statistical analysis revealed nine distinct groups (Table 1). This is in contrast to the intertidal MTB in the Qingdao Sea area, which have a single form $[12,17]$; it is speculated that this is related to the particular ecological environment of Weihai.

Optical microscopy observations show that magnetotactic cocci are dominant in the samples collected from the intertidalite near Xiaoshi Island. TEM observations revealed that these bacteria are highly diverse based on morphological features of cells and magnetosomes. At least nine distinct phenotypes (designated $\mathrm{MC} \mathrm{a}-\mathrm{i}$ ) can be recognized on the basis of cell size, magnetosome chains, magnetite crystals, and inclusion particles in the cells. MC $d$ is the most enriched in these groups under TEM observation. The size of all observed bacteria ranges between 1 and $4 \mu \mathrm{m}$. Two parallel or cross magnetosome chains are observed in $\mathrm{MC}$ a to $\mathrm{f}$, whereas $\mathrm{MC} \mathrm{g}$ has a single chain, and $\mathrm{MC} \mathrm{h}$ and $\mathrm{MC} \mathrm{i}$ have stacked magnetosomes (Figure 1). According to the recent reported references, MTB are found to display various cell morphologies, such as cocci, ovoid, bean-like shaped, rod shaped, spirilla, and a number of giant multicellular MTB [1-3]. Cell sizes are also very different, even in MTB with the same shape. For some magnetotactic cocci, the size of magnetoovoid MO-1 is about 1.3 by $1.8 \mu \mathrm{m}$ [15], while the stain SKK-01 from the OP3 division, also ovoidshaped, reaches 2.3 by $3.7 \mu \mathrm{m}$ [16]. Among the collected magnetotactic cocci, we detected the MC g type, which is very similar to the previous descriptions of south-seeking magnetotactic cocci within the Alphaproteobacteria [39].

Magnetosomes in these cocci are all prismatic, with average shape factors from 0.71 to 0.94 . The sizes of crystals range in length from 68 to $140 \mathrm{~nm}$ and in width from 51 to $122 \mathrm{~nm}$. These crystals are likely to be single-domain magnetites according to the theoretical prediction described by Butler and Banerjee [40]. The size distribution of the magnetic crystals from MC a-i cells was broader compared with the crystals from Magnetococcus marinus MC-1 and Magnetovibrio blakemorei MV-1 (Figure 2) [41].
Furthermore, the SAED pattern and the high resolution transmission electron microscopy (HRTEM) images indicated that magnetosomes produced by magnetococci $\mathrm{MC} h$ are well crystallized magnetite with hexagonal prism crystal morphology (Figures 3(b) and 3(c)). Analyses by EDXS revealed the "iron-oxide" composition of the magnetosome crystals in MC h (Figures 3(a), 3(d), and 3(e)) and two types of particles in the MC a, MC c, and MC d cells (Figures 3(f), $3(\mathrm{~g})$, and $3(\mathrm{~h}))$; one type of particle contains $\mathrm{O}$ and $\mathrm{S}$ as in $\mathrm{MC} \mathrm{c}$ (Figures 3(h) and 3(l)), while the other type contains $\mathrm{O}$, $\mathrm{Mg}, \mathrm{P}$, and $\mathrm{Ca}$ as in MC (Figures 3(f) and 3(i)). Interestingly, for the MC a bacteria, both particles are observed (Figures $3(\mathrm{~g}), 3(\mathrm{j})$, and $3(\mathrm{k}))$. X-ray spectroscopy analysis showed that magnetosomes from MTB of the intertidal area in Weihai were mainly composed of both $\mathrm{Fe}$ and $\mathrm{O}$ elements, which, combined with the diffraction SAED results, showed that the crystal type of magnetosome was magnetite. Furthermore, cells of these uncultured magnetotactic cocci contained three types of intracellular inclusions, a series of magnetosomes composed of magnetosome chains, that were crystals of magnetite. In addition, P-rich bodies and S-containing inclusions occupied the majority of the cell volume. The roles of these particles in the cell are not yet clear, and research in this area is relatively limited. According to Cox et al., the presence of these large P-rich and S-containing inclusions might be an indication of cell stress, or these inclusions may be important in cell buoyancy or in energy generation or useful as stored electron donors [42]. Because of their remarkable capacity of assimilation of iron, sulfur, phosphorus, and so on, MTB play an important role in the geochemical cycling in natural habitats. Moreover, considering their wide distribution in diverse aquatic and sedimentary ecosystems and their high intracellular iron content, MTB have global significance in bulk sedimentary magnetism and have numerous versatile applications in paleoenvironmental reconstructions and biotechnological and biomedical fields [6-9].

3.2. Phylogenetic Diversity of MTB. In this study, more than 70 positive clones were analyzed by RFLP, which can be defined as an operational taxonomic unit (OTU) and may often be inferred to be a single population within 


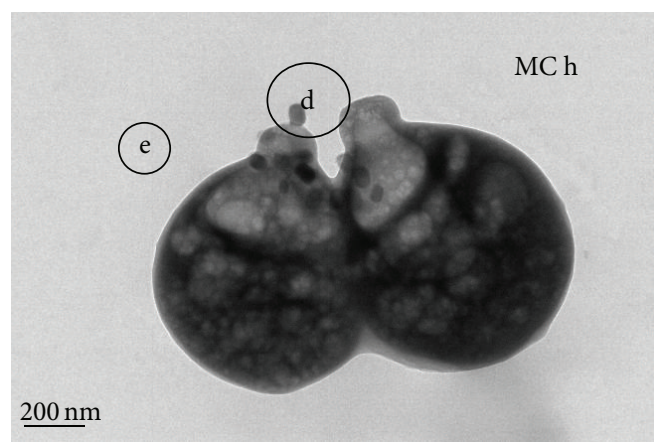

(a)

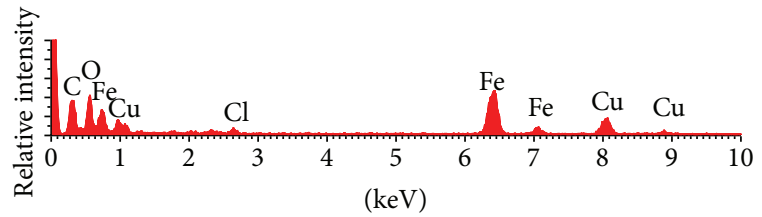

(d)

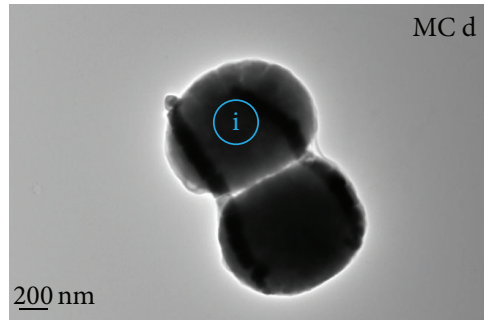

(f)

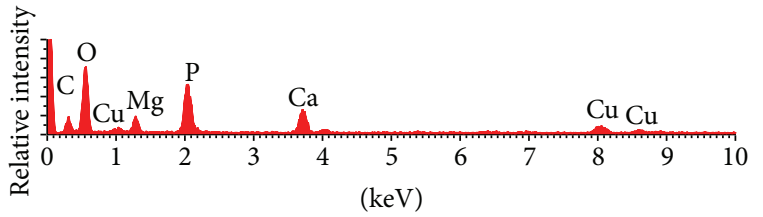

(i)

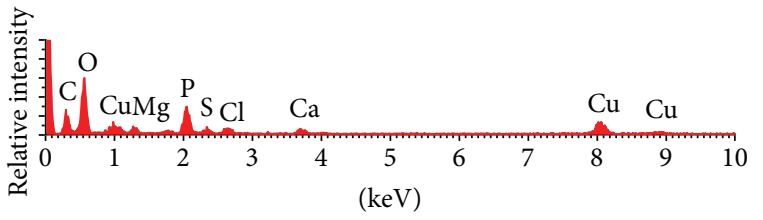

(k)

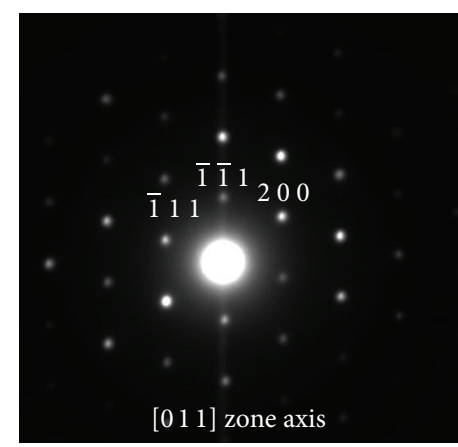

(b)

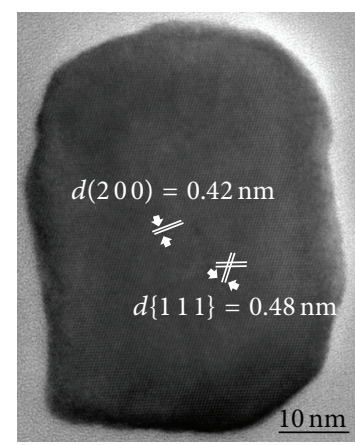

(c)

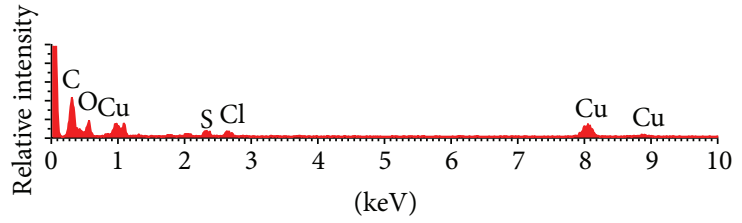

(e)

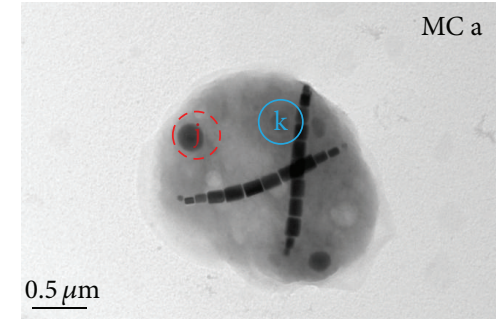

(g)

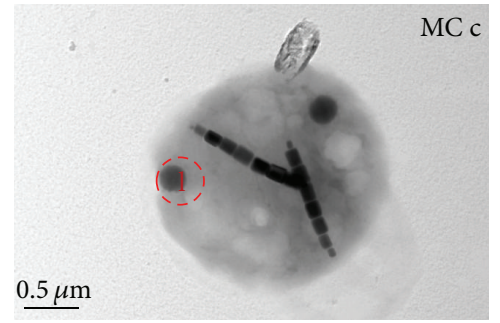

(h)

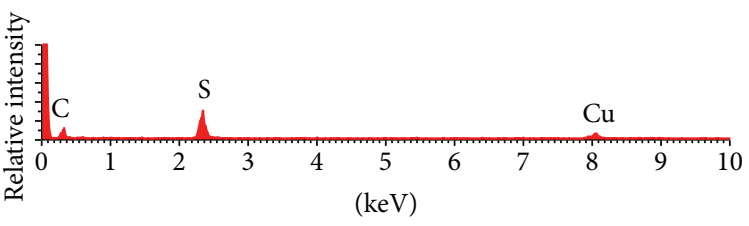

(j)

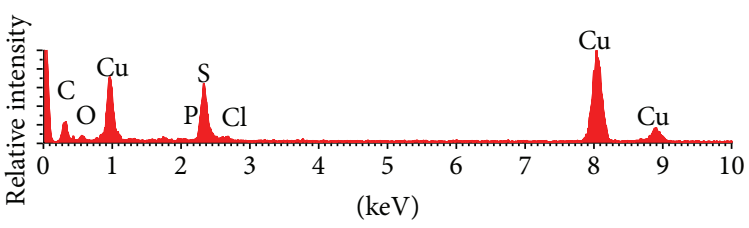

(1)

FIGURE 3: TEM images ( $\mathrm{a}, \mathrm{f}, \mathrm{g}$, and $\mathrm{h}$ ). Selected area electron diffraction (b) and HRTEM image (c) of a single, hexagonal prism crystal of magnetite. The diffraction pattern corresponds to the $\langle 011\rangle$ zone axis of the magnetite crystal. EDXS obtained from a crystal with visible iron oxides (d). EDXS obtained from a particle-free region (e). EDXS analysis of one globule (i) showing the important presence of O, Mg, P, and $\mathrm{Ca}$; labeled area in (f). EDXS analysis of two globules (j, k) showing the important presence of $\mathrm{O}, \mathrm{Mg}, \mathrm{P}, \mathrm{Ca}$, and S; labeled areas in (g). EDXS analysis of one globule (l) showing the important presence of S; labeled area in (h).

a community. There are seven OTUs in total, of which one OTU, designated WHI-2, accounts for the main maps. One to two representative clones of each OTU were then selected for sequencing and phylogenetic analysis (Figure 4). The results indicated that seven of these sequences show similarity to the vast majority of reported MTB sequences, with more than $85-97 \%$ identity, whereas others are far from the known MTB ( $<75 \%)$, indicating that these sequences were likely derived from the environmental pollution; therefore, these sequences would not be used in the subsequent analysis. All of these eight sequences (designated WHI-2, WHI-8, WHI9, WHI-14, WHI-17, WHI-18, WHI-27, and WHI-32) associate with the Alphaproteobacteria and are clustered closely to the unsequenced ovoid-coccoid magnetotactic bacteria. Through comparison to the NCBI nucleotide database using the BLAST algorithm, only WHI-32 had a high identity of $97 \%$ with the magnetotactic bacterium strain rij5, and the similarity of the other several strains was lower than 95\% [43]. 


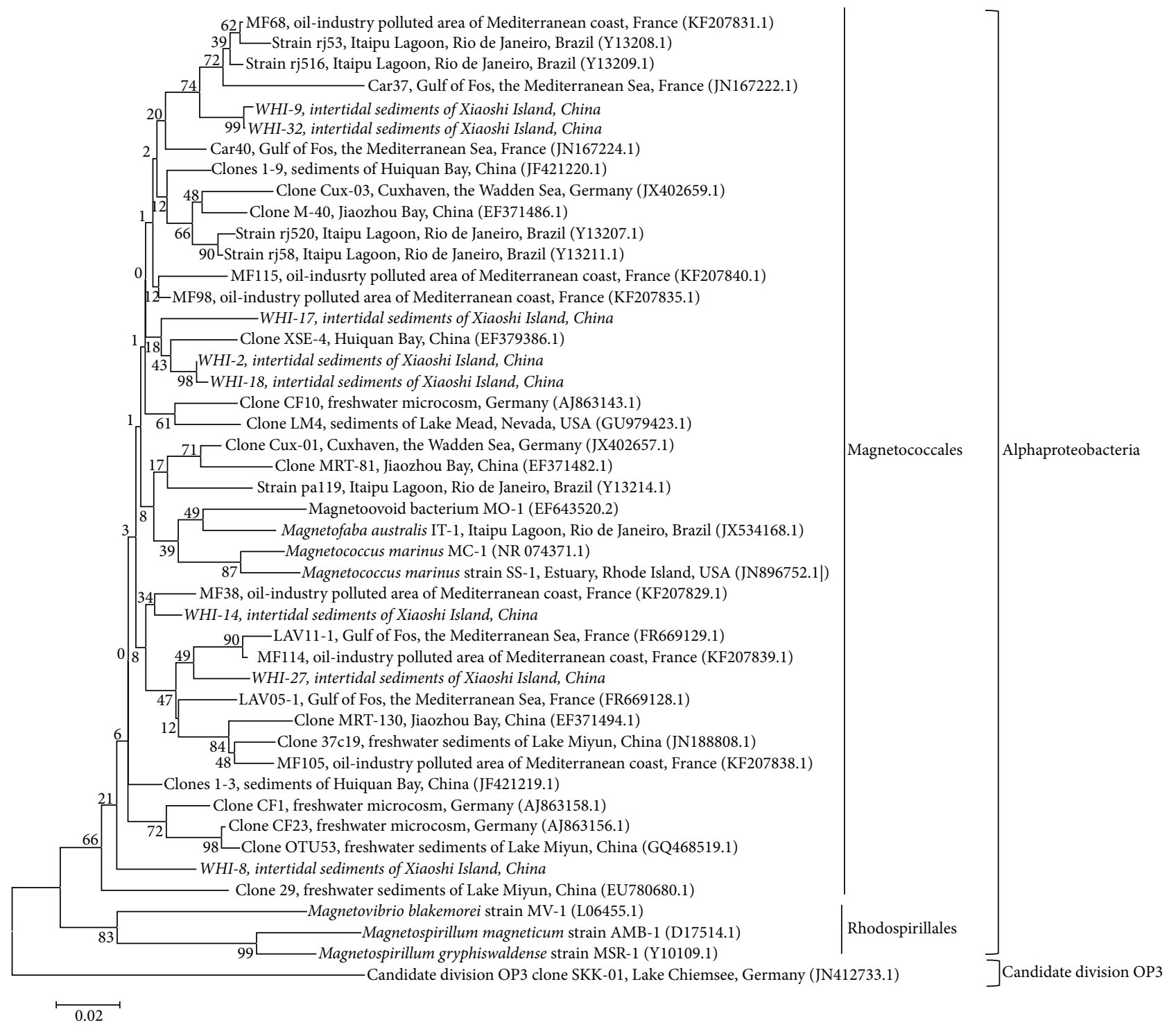

FIGURE 4: Phylogenetic tree showing the relationships between the 7 MTB OTUs in the Alphaproteobacteria. The tree was generated using neighbor-joining analysis. The numbers at nodes represent bootstrap values for the nodes (1000 times resampling analysis).

Because WHI-2 and WHI-18 share 99\% identity with each other (based on $\geq 98 \%$ genetic similarity to sequences from just one species), therefore, the other identified strains might correspond to new genera and species; so our results identified seven MTB species in the ovoid-coccoid magnetotactic bacteria of Xiaoshi Island.

Uncultured MTB in the environment are usually identified using fluorescence in situ hybridization analysis. It was confirmed that the sequences collected here originated from the enriched cocci. Based on the grouping of WHI-2 and WHI-18, a specific oligonucleotide probe, WHI-166, was designed to be complementary to these retrieved sequences and applied to fluorescence in situ hybridization of the MTB cells. Fluorescence microscopy revealed a strong signal, and the designed specific probes only recognized the magnetotactic cocci cells (Figure 5), whereas clones of E. coli could not be hybridized as controls (Figures $5(a)-5(c)$ ). These results suggested that the sequences WHI-2 and WHI-18 did come from a population of environment sample because they could be specifically hybridized with the specific probe (Figures $5(\mathrm{~d})-5(\mathrm{f}))$.

In our results for the phylogenetic tree, MTB belonging to the Alphaproteobacteria represent the dominant group in this marine environment, with magnetotactic cocci being the dominant type of MTB as reported in other studies worldwide [3]. The seven new strains of uncultured magnetococci formed a branch with purified and cultured Magnetococcus marinus MC-1, M. magneticum MS-1, and marine magnetic spirillum QH-2, which are Magnetococcales and therefore belong to the same order. The results show that the order Magnetococcalesin the Alphaproteobacteria constitute the major group of MTB, accounting for $90 \%$ of the total number of sequences described above and contributing to the genetic diversity in Weihai. Therefore, cloning and analysis of 


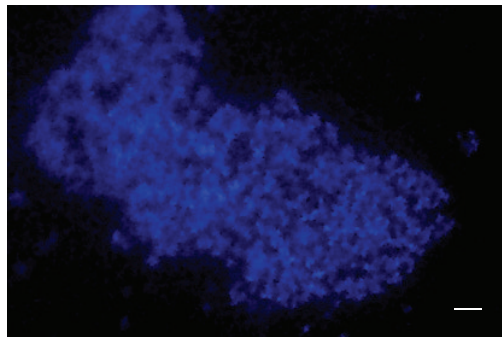

(a)

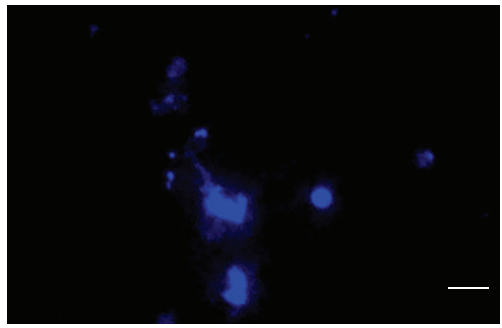

(d)

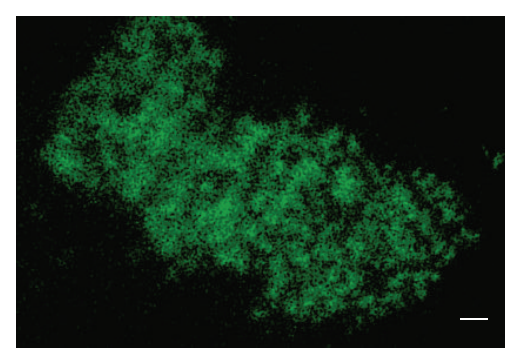

(b)

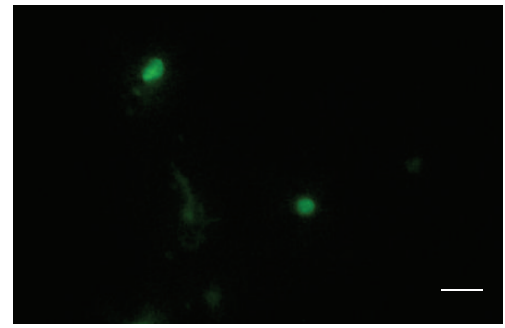

(e)

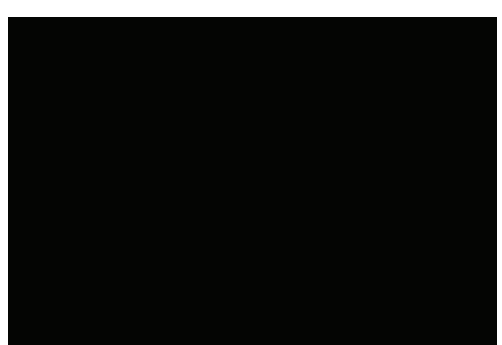

(c)

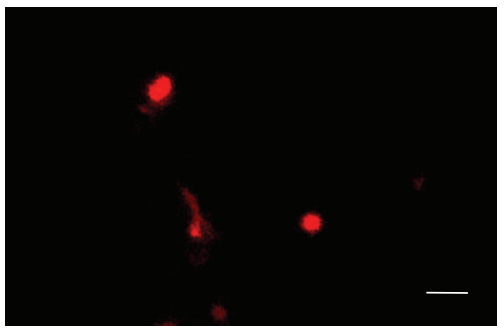

(f)

FIGURE 5: FISH analysis of negative controls of clones of E. coli (a to c) and MTB from Xiaoshi Island (d to f). In panels (a) to (c) and (d) to (f), the same microscopic fields are shown after staining with DAPI (a,d), after hybridization with the $5^{\prime}$-FAM-labeled bacterial universal probe EUB338 (b, e), and after hybridization with the $5^{\prime}$-Cy3-labeled probe WHI-166 (c, f). White bars indicate 10 microns.

magnetotactic species are powerful approaches for obtaining further insight into genetic diversity. The results showed that WHI-2 is one of the main species, with a prevalence of approximately $35 \%$. As expected, by designing probe WHI166 for FISH analysis, we observed excellent results. The WHI-17 16S rRNA gene sequence showed 94\% identity with the marine strain clone XSE-42 from the intertidal zone of Qingdao Huiquan Bay. The 16S rRNA gene sequences from all the other strains showed identity of $93 \%-88 \%$ with uncultured Magnetococcus sp. 1-9 collected from the intertidal zone in Huiquan Bay $[12,17]$. At the same time, compared with the strains Magnetococcus marinus MC-1, Magnetovibrio blakemorei MV-1, and magnetoovoid bacterium MO-1, among others, the maximum identity between the strains was only approximately $90 \%$; therefore, with the exception of WHI-32, all of these strains represent new genus, demonstrating that the Weihai intertidal zone has rich MTB diversity [44-46]. These results show that there were differences between the bacterial diversity of different regions; geographic distances may be a major factor affecting the distribution of MTB communities. It is important that we understand more about the distribution, habits, and population dynamics of MTB and the characteristics of their magnetosomes. Indeed, Edwards and Bazylinski stated that even when population sizes are small relative to other prokaryotic groups in aquatic, soil, and sediments, the impact that MTB, and the tiny crystals they produce, can have in present-day biogeochemical cycling can be large; and the magnetosomes minerals that make it to the geological rock record may serve as better paleoenvironmental indicators [47].

\section{Conclusions}

As demonstrated in our study, the wide range of cell sizes, the different magnetosome arrangements and crystal shape, and the large number of different retrieved 16S rRNA gene sequences suggest that the MTB of Weihai represent several different magnetotactic cocci. These data also increase the view of Alphaproteobacteria as a major and diversified class of MTB in marine environments. Our work highlights the most important diversity of MTB in Xiaoshi Island and develops a better understanding of the molecular ecology and biology of natural MTB cells.

Both live and dead magnetotactic bacterial cells have proven useful in environmental, magnetic, and nanomedical applications [3]. After the death of the MTB, the magnetite particles settle through the ambient water column forming part of the bottom sediments; such magnetites in sediments, which are of biogenic parentage, are called magnetofossils [48]. The single-domain magnetofossils preserved in sediments are not only ideal carriers of magnetization for paleomagnetism but also potential biomarkers for retrieving paleoenvironmental information [23, 49]. More research involving the distribution and ecology of MTB in nature, especially in marine habitats, will help us better understand the conditions under which and to what extent MTB affect the biogeochemical cycle and the present-day biogeography. In addition, bacterial magnetite magnetosomes may prove to be useful and perhaps superior to chemically produced magnetite nanoparticles in the medical applications [50]. However, the research for magnetosomes from MTB as carriers of genes or drugs for cancer therapy or other diseases is limited, thus providing a challenge for follow-up studies.

\section{Conflict of Interests}

The authors declare that there is no conflict of interests regarding the publication of this paper. 


\section{Acknowledgments}

The authors are grateful to Bo Tao for help in FISH observations. They thank Long-Fei Wu and Sheng-Da Zhang for useful discussion and suggestions. The authors also thank the anonymous reviewers and the editor for their valuable comments. This work was supported by Grant 2014YD02 from the Project of Academy Locality Science and Technology Cooperation of Sanya City, China. This work was also supported by State Key Laboratory of Microbial Technology Open Projects Fund (Project no. M2014-09).

\section{References}

[1] R. B. Frankel, "The discovery of magnetotactic/magnetosensitive bacteria," Chinese Journal of Oceanology and Limnology, vol. 27, no. 1, pp. 1-2, 2009.

[2] R. Blakemore, "Magnetotactic bacteria," Science, vol. 190, no. 4212, pp. 377-379, 1975.

[3] D. A. Bazylinski, C. T. Lefèvre, and D. Schüler, "Magnetotactic bacteria," in The Prokaryotes, pp. 453-494, Springer, 2013.

[4] J. H. Li, K. P. Ge, Y. X. Pan, W. Williams, Q. S. Liu, and H. F. Qin, "A very strong angular dependence of magnetic properties of magnetosome chains: implications for rock magnetism and paleomagnetism," Geochemistry, Geophysics, Geosystems, vol. 14, no. 10, pp. 3887-3907, 2013.

[5] J. H. Li, N. Menguy, C. Gatel et al., "Crystal growth of bulletshaped magnetite in magnetotactic bacteria of the Nitrospirae phylum," Journal of the Royal Society Interface, vol. 12, no. 103, Article ID 20141288, 2015.

[6] T. Prozorov, D. A. Bazylinski, S. K. Mallapragada, and R. Prozorov, "Novel magnetic nanomaterials inspired by magnetotactic bacteria: topical review," Materials Science \& Engineering R: Reports, vol. 74, no. 5, pp. 133-172, 2013.

[7] J. H. Li, K. Benzerara, S. Bernard, and O. Beyssac, "The link between biomineralization and fossilization of bacteria: insights from field and experimental studies," Chemical Geology, vol. 359, pp. 49-69, 2013.

[8] D. Faivre and T. U. Godec, "From bacteria to mollusks: the principles underlying the biomineralization of iron oxide materials," Angewandte Chemie-International Edition, vol. 54, no. 16, pp. 4728-4747, 2015.

[9] B. Kim, K. P. Kodama, and R. E. Moeller, "Bacterial magnetite produced in water column dominates lake sediment mineral magnetism: Lake Ely, USA," Geophysical Journal International, vol. 163, no. 1, pp. 26-37, 2005.

[10] W. Lin, J. H. Li, and Y. X. Pan, "Newly isolated but uncultivated magnetotactic bacterium of the phylum Nitrospirae from Beijing, China," Applied and Environmental Microbiology, vol. 78, no. 3, pp. 668-675, 2012.

[11] A. Isambert, N. Menguy, E. Larquet, F. Guyot, and J.-P. Valet, "Transmission electron microscopy study of magnetites in a freshwater population of magnetotactic bacteria," American Mineralogist, vol. 92, no. 4, pp. 621-630, 2007.

[12] H.-M. Pan, K.-L. Zhu, T. Song et al., "Characterization of a homogeneous taxonomic group of marine magnetotactic cocci within a low tide zone in the China Sea," Environmental Microbiology, vol. 10, no. 5, pp. 1158-1164, 2008.

[13] W. Lin, J. Li, D. Schüler, C. Jogler, and Y. Pan, "Diversity analysis of magnetotactic bacteria in Lake Miyun, northern China, by restriction fragment length polymorphism," Systematic and Applied Microbiology, vol. 32, no. 5, pp. 342-350, 2009.

[14] C. Lefèvre, A. Bernadac, N. Pradel et al., "Characterization of Mediterranean magnetotactic bacteria," Journal of Ocean University of China, vol. 6, no. 4, pp. 355-359, 2007.

[15] C. T. Lefèvre, A. Bernadac, K. Yu-Zhang, N. Pradel, and L.$\mathrm{F}$. $\mathrm{Wu}$, "Isolation and characterization of a magnetotactic bacterial culture from the Mediterranean Sea," Environmental Microbiology, vol. 11, no. 7, pp. 1646-1657, 2009.

[16] S. Kolinko, C. Jogler, E. Katzmann, G. Wanner, J. Peplies, and D. Schüler, "Single-cell analysis reveals a novel uncultivated magnetotactic bacterium within the candidate division OP3," Environmental Microbiology, vol. 14, no. 7, pp. 1709-1721, 2012.

[17] W.-Y. Zhang, K. Zhou, H.-M. Pan et al., "Two genera of magnetococci with bean-like morphology from intertidal sediments of the Yellow Sea, China," Applied and Environmental Microbiology, vol. 78, no. 16, pp. 5606-5611, 2012.

[18] H. Petermann and U. Bleil, "Detection of live magnetotactic bacteria in South Atlantic deep-sea sediments," Earth and Planetary Science Letters, vol. 117, no. 1-2, pp. 223-228, 1993.

[19] C. T. Lefèvre, F. Abreu, M. L. Schmidt et al., "Moderately thermophilic magnetotactic bacteria from hot springs in Nevada," Applied and Environmental Microbiology, vol. 76, no. 11, pp. 3740-3743, 2010.

[20] C. T. Lefèvre, R. B. Frankel, M. Pósfai, T. Prozorov, and D. A. Bazylinski, "Isolation of obligately alkaliphilic magnetotactic bacteria from extremely alkaline environments," Environmental Microbiology, vol. 13, no. 8, pp. 2342-2350, 2011.

[21] C. T. Lefèvre and L.-F. Wu, "Evolution of the bacterial organelle responsible for magnetotaxis," Trends in Microbiology, vol. 21, no. 10, pp. 534-543, 2013.

[22] S. Spring, R. Amann, W. Ludwig et al., "Phylogenetic analysis of uncultured magnetotactic bacteria from the alpha-subclass of Proteobacteria," Systematic and Applied Microbiology, vol. 17, no. 4, pp. 501-508, 1995.

[23] W. Lin, D. A. Bazylinski, T. Xiao, L.-F. Wu, and Y. Pan, "Life with compass: diversity and biogeography of magnetotactic bacteria," Environmental Microbiology, vol. 16, no. 9, pp. 26462658, 2014.

[24] Y. Okamura, H. Takeyama, and T. Matsunaga, "Twodimensional analysis of proteins specific to the bacterial magnetic particle membrane from Magnetospirillum sp. AMB1," Applied Biochemistry and Biotechnology, vol. 84-86, no. 1-9, pp. 441-446, 2000.

[25] D. Schüler and M. Köhler, "The isolation of a new magnetic spirillum," Zentralblatt für Mikrobiologie, vol. 147, no. 1-2, pp. 150-151, 1992.

[26] M. Greenberg, K. Canter, I. Mahler, and A. Tornheim, "Observation of magnetoreceptive behavior in a multicellular magnetotactic prokaryote in higher than geomagnetic fields," Biophysical Journal, vol. 88, no. 2, pp. 1496-1499, 2005.

[27] D. Schüler, "The biomineralization of magnetosomes in Magnetospirillum gryphiswaldense," International Microbiology, vol. 5, no. 4, pp. 209-214, 2002.

[28] W. Lin and Y. X. Pan, "Temporal variation of magnetotactic bacterial communities in two freshwater sediment microcosms," FEMS Microbiology Letters, vol. 302, no. 1, pp. 85-92, 2010.

[29] C. Jogler, W. Lin, A. Meyerdierks et al., "Toward cloning of the magnetotactic metagenome: identification of magnetosome island gene clusters in uncultivated magnetotactic bacteria from different aquatic sediments," Applied and Environmental Microbiology, vol. 75, no. 12, pp. 3972-3979, 2009. 
[30] W. Lin, C. Jogler, D. Schüler, and Y. X. Pan, Bidirectional Magnetotactic Bacteria Collecting Device Useful for Researching Variability and Magnetic Performance of Magnetotactic Bacteria, Comprises a Collector, a Separation Tube, a Sample Tube, a Helmholtz Coil, and a Coil Controller, Institute of Geology and Geophysics, Chinese Academy of Sciences, Beijing, China, 2009.

[31] J. H. Li, X. Ge, X. K. Zhang, G. J. Chen, and Y. X. Pan, "Recover vigorous cells of Magnetospirillum magneticum AMB-1 by capillary magnetic separation," Chinese Journal of Oceanology and Limnology, vol. 28, no. 4, pp. 826-831, 2010.

[32] J. Li, Y. Pan, Q. Liu et al., "Biomineralization, crystallography and magnetic properties of bullet-shaped magnetite magnetosomes in giant rod magnetotactic bacteria," Earth and Planetary Science Letters, vol. 293, no. 3-4, pp. 368-376, 2010.

[33] J. D. Thompson, D. G. Higgins, and T. J. Gibson, "CLUSTAL W: improving the sensitivity of progressive multiple sequence alignment through sequence weighting, position-specific gap penalties and weight matrix choice," Nucleic Acids Research, vol. 22, no. 22, pp. 4673-4680, 1994.

[34] M. T. Brandl, B. Quiñones, and S. E. Lindow, "Heterogeneous transcription of an indoleacetic acid biosynthetic gene in Erwinia herbicola on plant surfaces," Proceedings of the National Academy of Sciences of the United States of America, vol. 98, no. 6, pp. 3454-3459, 2001.

[35] J. R. Cole, Q. Wang, E. Cardenas et al., "The Ribosomal Database Project: improved alignments and new tools for rRNA analysis," Nucleic Acids Research, vol. 37, supplement 1, pp. D141-D145, 2009.

[36] A. Pernthaler, J. Pernthaler, and R. Amann, "Fluorescence in situ hybridization and catalyzed reporter deposition for the identification of marine bacteria," Applied and Environmental Microbiology, vol. 68, no. 6, pp. 3094-3101, 2002.

[37] J. Pernthaler, F.-O. Glöckner, W. Schönhuber, and R. Amann, "Fluorescence in situ hybridization (FISH) with rRNA-targeted oligonucleotide probes," Methods in Microbiology, vol. 30, pp. 207-226, 2001.

[38] W. Lin and Y. X. Pan, "Uncultivated magnetotactic cocci from Yuandadu Park in Beijing, China," Applied and Environmental Microbiology, vol. 75, no. 12, pp. 4046-4052, 2009.

[39] V. Morillo, F. Abreu, A. C. Araujo et al., "Isolation, cultivation and genomic analysis of magnetosome biomineralization genes of a new genus of South-seeking magnetotactic cocci within the Alphaproteobacteria," Frontiers in Microbiology, vol. 5, article 72, 2014.

[40] R. F. Butler and S. K. Banerjee, "Theoretical single-domain grain size range in magnetite and titanomagnetite," Journal of Geophysical Research, vol. 80, no. 29, pp. 4049-4058, 1975.

[41] B. Devouard, M. Pósfai, X. Hua, D. A. Bazylinski, R. B. Frankel, and P. R. Buseck, "Magnetite from magnetotactic bacteria: size distributions and twinning," American Mineralogist, vol. 83, no. 11-12, pp. 1387-1398, 1998.

[42] B. L. Cox, R. Popa, D. A. Bazylinski et al., "Organization and elemental analysis of $\mathrm{P}$-, S-, and Fe-rich inclusions in a population of freshwater magnetococci," Geomicrobiology Journal, vol. 19, no. 4, pp. 387-406, 2010.

[43] S. Spring, U. Lins, R. Amann et al., "Phylogenetic affiliation and ultrastructure of uncultured magnetic bacteria with unusually large magnetosomes," Archives of Microbiology, vol. 169, no. 2, pp. 136-147, 1998.

[44] N. H. C. Sparks, S. Mann, D. A. Bazylinski, D. R. Lovley, H. W. Jannasch, and R. B. Frankel, "Structure and morphology of magnetite anaerobically-produced by a marine magnetotactic bacterium and a dissimilatory iron-reducing bacterium," Earth and Planetary Science Letters, vol. 98, no. 1, pp. 14-22, 1990.

[45] F. C. Meldrum, S. Mann, B. R. Heywood, R. B. Frankel, and D. A. Bazylinski, "Electron microscopy study of magnetosomes in a cultured coccoid magnetotactic bacterium," Proceedings of the Royal Society B: Biological Sciences, vol. 251, no. 1332, pp. 231236, 1993.

[46] W.-J. Zhang, C. Chen, Y. Li, T. Song, and L.-F. Wu, "Configuration of redox gradient determines magnetotactic polarity of the marine bacteria MO-1," Environmental Microbiology Reports, vol. 2, no. 5, pp. 646-650, 2010.

[47] K. J. Edwards and D. A. Bazylinski, "Intracellular minerals and metal deposits in prokaryotes," Geobiology, vol. 6, no. 3, pp. 309317, 2008.

[48] J. L. Kirschvink and S. R. Chang, "Ultrafine-grained magnetite in deep-sea sediments: possible bacterial magnetofossils.," Geology, vol. 12, no. 9, pp. 559-562, 1984.

[49] R. E. Kopp, D. Schumann, T. D. Raub et al., "An Appalachian Amazon? Magnetofossil evidence for the development of a tropical river-like system in the mid-Atlantic United States during the Paleocene-Eocene thermal maximum," Paleoceanography, vol. 24, no. 4, 2009.

[50] J. B. Sun, J. H. Duan, S. L. Dai et al., "In vitro and in vivo antitumor effects of doxorubicin loaded with bacterial magnetosomes (DBMs) on $\mathrm{H} 22$ cells: the magnetic bio-nanoparticles as drug carriers," Cancer Letters, vol. 258, no. 1, pp. 109-117, 2007. 

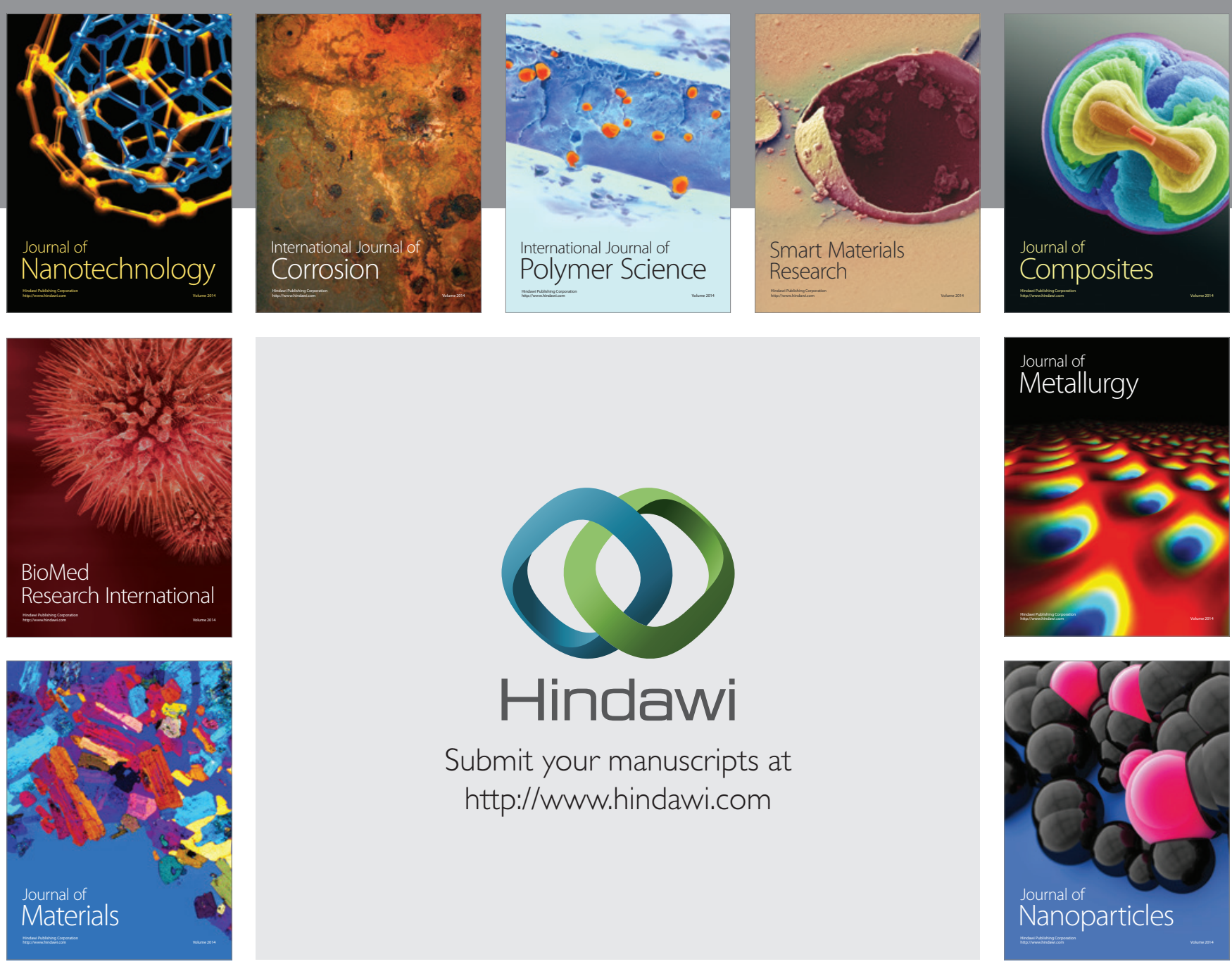

Submit your manuscripts at http://www.hindawi.com
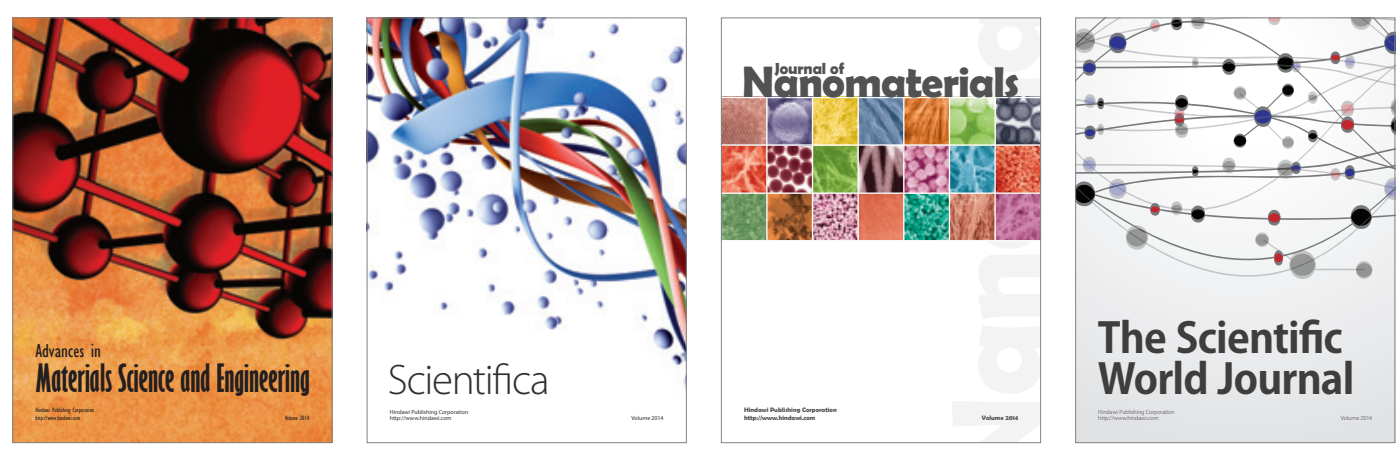

\section{The Scientific World Journal}
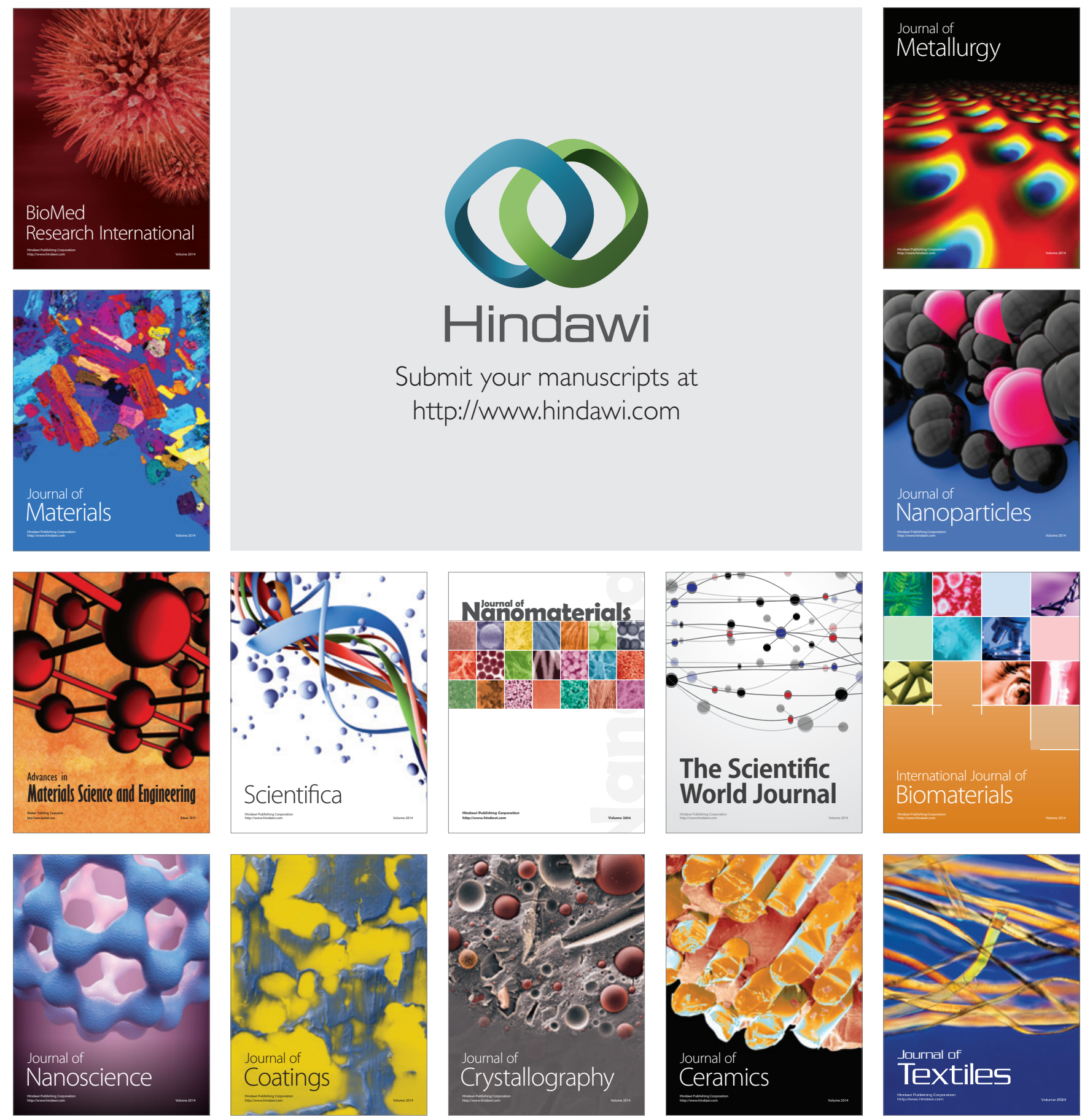